\title{
COVID-19 Pandemic and Anxiety Related Factors in Patients Treated in the Emergency Department
}

\author{
Vahide Aslihan Durak ${ }^{1, *}$, Seyda Gunay ${ }^{2}$, Deniz Sigirli ${ }^{3}$, Bedrettin Akova ${ }^{4}$, \\ Erol Armagan ${ }^{1}$
}

\author{
${ }^{1}$ Emergency Medicine Department, \\ Uludag University Medical Faculty, \\ Bursa, Turkey \\ ${ }^{2}$ Cardiology Department, Uludag \\ University Medical Faculty, Bursa, Turkey \\ ${ }^{3}$ Biostatistics Department, Uludag \\ University Medical Faculty, Bursa, Turkey \\ ${ }^{4}$ Sports Medicine Department, Uludag \\ University Medical Faculty, Bursa, Turkey

\section{*Correspondence} \\ aslidurakis@hotmail.com \\ (Vahide Aslihan DURAK)
}

\begin{abstract}
Aims: A novel coronavirus, now known as SARS-CoV-2019, suddenly emerged in Wuhan, China and within threemonths of the initial outbreak, the virus had spread rapidly to neighboring countries causing a pandemic. After the first case was announced, emergency departments were immediately reorganized as pandemic clinics. Special areas with maximum precautions were designed to evaluate patients. The majority of studies on this pandemic have focused on the treatment of respiratory symptoms and comorbidities in intensive care units. In this study, we sought to determine those factors that contributed to the anxiety level during the COVID-19 pandemic using the 'State' subscale of State-Trait Anxiety Inventory (STAI-S). Methods: A survey was performed in the emergency department by using an online questionnaire which consisted of demographic variables, questions about the opinions and behaviors of patients during the pandemic, diagnostic test results for COVID-19, and treatment methods. Results: There was a statistically significant difference between employment status $(p<0.001)$, monthly income $(\mathrm{p}<0.001)$, the food consumption changes during the pandemic period $(p=0.001)$ and the estimated end-date for the COVID-19 pandemic $(p<0.001)$ and total STAI-S points. Conclusions: Our study has identified factors which significantly increase anxiety during the COVID-19 pandemic and identified those individuals who may benefit from psychiatric and social support.
\end{abstract}

\section{Keywords}

Anxiety, COVID-19, Emergency department

\section{Introduction}

In late 2019, a novel coronavirus, now known as SARSCoV-2019, suddenly emerged in Wuhan, China [1]. Within three months of the initial outbreak, the virus has spread rapidly world-wide resulting in a pandemic. The first coronavirus case was confirmed in Turkey on March 11,2020. A 'voluntary quarantine' was advised by the government to reduce the spread of the virus and protect older age groups especially those with chronic diseases. During April and May,an 'obligatory quarantine' on weekends as well as the use of personal protective equipment (such as face masks and shields)was approved.Emergencydepartments were immediately reorganized as pandemic clinics and specified areas with high precautions were designed in which patients could be initially evaluated.Groups of doctors named as 'team pandemic' were organized in every hospital; which included members from infectious diseases, pulmonary diseases, internal medicine and emergency medicine departments.

During the pandemic period, health professionals mainly focused on the treatment of respiratory symptoms and comorbidities in clinical and intensive care units. However, these pandemicsmay also have devastating psychological and social effects on adults, children and communities [2-4]. In Australia, an increased risk of psychiatric disorders have been associated with natural and man-made disasters [5]. Another study which was performed to determine the anxiety levels after the Fukushima Daiichi Nuclear Power Station Accident showed that emotional stress levels were increased after the incident [6]. Similar studies showed increased anxiety levels after earthquakes and hurricanes $[7,8]$.

Studies have alsobeen performed on health care workers and the general population to assess changes in mental health during the COVID-19 pandemic [1-3].

In this study, we sought to determine the sociodemographic characteristics of a heterogenous population including patients and their relatives seen in the emergency department and health care workers at a university hospital during the COVID-19 pandemic to assess the anxiety levels by using the 'State' subscale of State-Trait Anxiety Inventory(STAI-S) which is widely used for screening anxiety in the general population, psychiatric and somatic patients $[9,10]$. 
TA B L E 1. The sociodemographic characteristics of the participants.

\begin{tabular}{|c|c|c|c|}
\hline Sociodemographic characteristics & & $\mathbf{n}$ & $\%$ \\
\hline \multirow[t]{2}{*}{ Gender } & Male & 760 & 40.86 \\
\hline & Female & 1100 & 59.14 \\
\hline \multirow[t]{4}{*}{ Education } & Primary school & 70 & 3.76 \\
\hline & Secondary school & 104 & 5.59 \\
\hline & High school & 337 & 18.12 \\
\hline & University & 1349 & 72.53 \\
\hline \multirow[t]{7}{*}{ Employment status } & Government official & 273 & 14.68 \\
\hline & Employee with government insurance & 636 & 34.19 \\
\hline & Tradesman & 148 & 7.96 \\
\hline & Health care worker & 483 & 25.97 \\
\hline & Student & 51 & 2.74 \\
\hline & Housewife & 117 & 6.29 \\
\hline & Retired & 152 & 8.17 \\
\hline \multirow[t]{4}{*}{ Monthly income } & Lower than 3000 £ & 82 & 4.41 \\
\hline & About $3000 £$ & 352 & 18.93 \\
\hline & 3000-5000 & 768 & 41.31 \\
\hline & Higher than $5000 €$ & 657 & 35.34 \\
\hline \multirow[t]{2}{*}{ Marital status } & Married & 1325 & 71.24 \\
\hline & Single & 535 & 28.76 \\
\hline \multirow[t]{2}{*}{ Parental status } & Children & 1239 & 66.61 \\
\hline & No children & 621 & 33.39 \\
\hline \multirow[t]{6}{*}{ Household status } & Single & 212 & 11.40 \\
\hline & Married & 290 & 15.59 \\
\hline & Married with children & 904 & 48.60 \\
\hline & Single with child/children & 48 & 2.58 \\
\hline & With my wife/husband children and elderly relatives & 122 & 6.56 \\
\hline & Only with parents & 284 & 15.27 \\
\hline \multirow[t]{2}{*}{ Accompanying chronic diseases } & Yes & 524 & 28.20 \\
\hline & No & 1334 & 71.80 \\
\hline \multirow[t]{2}{*}{ Accompanying psychiatric diseases } & Yes & 144 & 7.74 \\
\hline & No & 1716 & 92.26 \\
\hline \multirow[t]{2}{*}{ Smoker } & Yes & 644 & 34.70 \\
\hline & No & 1212 & 65.30 \\
\hline
\end{tabular}

\section{Methods}

The survey was performed in the Emergency Department of a university hospital in May 2020 Patients seen in the Emergency Department, their relatives or friends and the health care workers participated in the study. The ages of the participants were between $18-80$ years old and the male/female ratio was 0.69 (760 male patients and 1100 female patients).

Ethical approval was obtained from the Scientific Research Commitee of Ministry of Health and Clinical Researches Ethical Commitee of the Uludag University Medical Faculty (2020-8/14).

The survey used an online questionnaire via 'Google Forms' and was sent to the participants as a link by WhatssApp or E- mail. Informed consent and the aim of the study were included in the questionnaire and 1860 participants were included in the survey.

According to the literature the prevelance of an anxiety disorder wasestimated to be between $5-6 \%$ [10]. The survey was planned to besent to 2608 participants; the minimum number of participants to be involved was calculated as 1825 .

The questionnaire consisted of demographic variables (such as educational attainment, employment status, monthly income, marital/household status, status as a parent and smoking habits), questions about the opinions and behaviours of participants during the pandemic (such as daily hand wash frequency, activities missed during the quarantine, changes 
TA B L E 2. Association between sociodemographic variables and STAI-S scores.

\begin{tabular}{|c|c|c|c|}
\hline Sociodemographic variables & Median Value & Minimum -Maximum value & p value \\
\hline \multicolumn{3}{|l|}{ Gender } & \multirow{3}{*}{$<0.001$} \\
\hline Male $(\mathrm{n}=750)$ & 42 & $20-80$ & \\
\hline Female $(n=1084)$ & 47 & $20-80$ & \\
\hline \multicolumn{4}{|l|}{ Education } \\
\hline Primary school $n=69$ ) & 43 & $20-76$ & \multirow{4}{*}{0.206} \\
\hline Secondary school $(\mathrm{n}=103)$ & 46 & $20-69$ & \\
\hline High school $(\mathrm{n}=331)$ & 45 & $20-80$ & \\
\hline University $(\mathrm{n}=1331)$ & 46 & $20-80$ & \\
\hline \multicolumn{4}{|l|}{ Employment status } \\
\hline Government official $(\mathrm{n}=273)$ & 47 & $20-80$ & \multirow{7}{*}{$<0.001$} \\
\hline Employee with government insurance $(n=623)$ & 44 & $20-77$ & \\
\hline Tradesman $(n=146)$ & 43.5 & $20-71$ & \\
\hline Health care worker(doctos,nurses, paramedics) $(n=478)$ & 48 & $21-80$ & \\
\hline Student $(\mathrm{n}=51)$ & 43 & $24-69$ & \\
\hline Housewife $(\mathrm{n}=114)$ & 48 & $22-77$ & \\
\hline Retired $(n=149)$ & 44 & $20-71$ & \\
\hline \multicolumn{4}{|l|}{ Monthly income } \\
\hline Lower than 3000TL $(n=81)$ & 47 & $20-77$ & \multirow{4}{*}{$<0.001$} \\
\hline About 3000 TL $(n=346)$ & 46 & $20-80$ & \\
\hline $3000-5000 T L(n=756)$ & 47 & $20-80$ & \\
\hline Higher than 5000TL $(n=650)$ & 43 & $20-79$ & \\
\hline \multicolumn{4}{|l|}{ Household status } \\
\hline Single $(n=207)$ & 47 & $20-80$ & \multirow{6}{*}{0.001} \\
\hline Married $(n=289)$ & 44 & $20-80$ & \\
\hline Married with child/children $(n=887)$ & 46 & $20-80$ & \\
\hline Single with child/children $(n=48)$ & 47.5 & $20-71$ & \\
\hline Married with children and elderly relatives $(n=120)$ & 47 & $20-80$ & \\
\hline Single with parents $(n=283)$ & 45 & $20-77$ & \\
\hline \multicolumn{4}{|l|}{ Accompanying psychiatric diseases } \\
\hline Yes $(n=143)$ & 53 & $20-80$ & \multirow{2}{*}{$<0.001$} \\
\hline No $(n=1691)$ & 45 & $20-80$ & \\
\hline \multicolumn{4}{|l|}{ Smoker } \\
\hline Yes $(n=635)$ & 46 & $20-80$ & \multirow{2}{*}{0.175} \\
\hline No $(n=1196)$ & 45 & $20-80$ & \\
\hline
\end{tabular}

in smoking habits, having anxiety about the possibility of death and the most important cause of anxiety during the pandemic),test results, treatment methods received and in the STAI-S subscale.

STAI is a psychological inventory based on a 4-point Likert scale and consists of 40 questions on a self-report basis [11].

There are 2 subscales within this measure. The State Anxiety Scale (S-Anxiety) evaluates the current state of anxiety, asking how respondents feel "right now" using items that measure subjective feelings of apprehension, tension, nervousness, worry and activation/arousal of the autonomic nervous system. The Trait Anxiety Scale (T-Anxiety) evaluates relatively stable aspects of "anxiety proneness" including general states of calmness, confidence and security $[11,12]$.

The STAI-S comprises 20 items. Items are answered on a 4-point Likert scale ranging from 1 (not at all) to 4 (very much so) with the total score ranging from 20 to 80 with higher scores indicating higher levels of anxiety symptoms. A cutoff score of 40 is commonly used to define probable clinical levels of anxiety. The STAI-S has shown to be a valid and reliable measure for determing anxiety [13].

The Turkish language version of STAI was performed by Oner and Le Compte in 1975 and test retest reliability coefficients ranged between 0.76 and 0.86 for Trait anxiety and 0.26 
TA B L E 3. Association between daily life habits and STAI - S scores.

\begin{tabular}{|c|c|c|c|}
\hline Variables & Median value & Minimum - Maximum value & p value \\
\hline \multicolumn{4}{|l|}{ Most important activity missed during the quarantine period } \\
\hline Travelling to other countries $(n=466)$ & 47 & $20-80$ & 0.011 \\
\hline Going to beauty or spa centers $(n=49)$ & 47 & $20-76$ & \\
\hline Dining outside in restaurants or cafes $(n=240)$ & 43 & $20-79$ & \\
\hline Going to work instead of working at home $(n=112)$ & 47 & $20-73$ & \\
\hline Social activities with friends $(n=967)$ & 46 & $20-80$ & \\
\hline \multicolumn{4}{|l|}{ Frequency of daily hand - washing during the pandemic } \\
\hline Increased $(n=1529)$ & 47 & $20-80$ & $<0.001$ \\
\hline Unchanged $(\mathrm{n}=305)$ & 41 & $20-74$ & \\
\hline \multicolumn{4}{|l|}{ Sanitizing of market products during the pandemic } \\
\hline Yes $(n=1458)$ & 47 & $20-80$ & $<0.001$ \\
\hline No $(n=376)$ & 43 & $20-72$ & \\
\hline \multicolumn{4}{|l|}{ Smoking has increased during pandemic } \\
\hline Yes $(n=168)$ & 55 & $20-80$ & $<0.001$ \\
\hline No $(n=463)$ & 44 & $20-77$ & \\
\hline \multicolumn{4}{|l|}{ Covid - 19 related deaths among your family members } \\
\hline Yes $(n=238)$ & 49 & $20-80$ & $<0.001$ \\
\hline $\operatorname{No}(n=1595)$ & 45 & $20-80$ & \\
\hline Having anxiety about the possibility of death due to Covid - 19 & & & $<0.001$ \\
\hline Yes $(n=1552)$ & 47 & $20-80$ & \\
\hline No $(n=282)$ & 39 & $20-73$ & \\
\hline \multicolumn{4}{|l|}{ The most important cause of anxiety during the pandemic } \\
\hline Becoming infected with the virus $(n=176)$ & 49 & $20-80$ & 0.001 \\
\hline Viral infection risk of family members $(n=1289)$ & 45 & $20-80$ & \\
\hline Needing intensive care unit $(\mathrm{n}=280)$ & 46 & $20-80$ & \\
\hline Decrease in income due to unemployment $(\mathrm{n}=87)$ & 45 & $20-73$ & \\
\hline \multicolumn{4}{|l|}{ Food consumption during the pandemic } \\
\hline Increased $(n=544)$ & 50 & $20-80$ & $<0.001$ \\
\hline Decreased $(n=151)$ & 53 & $20-80$ & \\
\hline No change $(n=1139)$ & 42 & $20-75$ & \\
\hline \multicolumn{4}{|l|}{ The effect of television programs on anxiety } \\
\hline Decrease in anxiety $(n=528)$ & 40 & $20-80$ & $<0.001$ \\
\hline Increase in anxiety $(\mathrm{n}=1306)$ & 48 & $20-80$ & \\
\hline
\end{tabular}

and 0.68 for State anxiety [14].

The Cronbach alpha reliability coefficient of our sample was found to be 0.932 in our study.

\section{Statistical Analysis}

The Shapiro-Wilk test was used to test variable normality. Normally distributed variables are presented as the mean (standard deviation). Variables that were not normally distributed are presented as median (minimum-maximum) values and were compared using the Mann-Whitney U test between two independent samples and Kruskal-Wallis test between more than two indepedendent groups. Categorical variables were presented with $\mathrm{n}(\%)$ values. The level required for statistical significance was $\alpha=0.05$ and statistical analyses were performed with IBM SPSS Statistics 21 software.

\section{Results}

The questionnaire was answered by 1860 participants. The median age was 39 (minimum-maximum: 18 - 80) years and the median score of STAI-S was 46 (minimum-maximum: 20 - 80).760 of the participants $(40,86 \%)$ were male and 1100 of the participants $(59,14 \%)$ were female. The demographic characteristics of the participants are listed in Table 1.

In the correlation analysis, there was a negatively significant 
TA B L E 4. Association between other COVID - 19 associated variables and STAI - S scores.

\begin{tabular}{|c|c|c|c|}
\hline Variables & Median value & Minimum - Maximum value & p value \\
\hline \multicolumn{4}{|l|}{ COVID - 19 Testing } \\
\hline Not performed $(n=1647)$ & 45 & $20-80$ & $<0.001$ \\
\hline Test performed $(\mathrm{n}=187)$ & 52 & $20-80$ & \\
\hline \multicolumn{4}{|l|}{ COVID - 19 Test Result } \\
\hline Positive $(\mathrm{n}=19)$ & 51 & $31-79$ & 0.133 \\
\hline Negative $(n=165)$ & 52 & $20-80$ & \\
\hline \multicolumn{4}{|l|}{ Treatment method } \\
\hline Short term hospitalization in a pandemic clinic $(n=17)$ & 51 & $31-79$ & 0.124 \\
\hline Quarantine at home $(n=63)$ & 47 & $20-80$ & \\
\hline No treatment received (1751) & 46 & $20-80$ & \\
\hline \multicolumn{4}{|l|}{ Opinion about the COVID-19 vaccine } \\
\hline I will get vaccinated when it is developed $(n=645)$ & 46 & $20-80$ & 0.003 \\
\hline I have not enough knowledge about the vaccine $(\mathrm{n}=997)$ & 46 & $20-80$ & \\
\hline $\begin{array}{l}\text { I will not get vaccinated, I believe it is not protective from } \\
\text { COVID }-19(n=191)\end{array}$ & 42 & $20-80$ & \\
\hline \multicolumn{4}{|l|}{ The estimated end - date for the COVID-19 pandemic } \\
\hline I have no hope that pandemic will end $(n=315)$ & 48 & $20-80$ & $<0.001$ \\
\hline 3 months $(\mathrm{n}=127)$ & 40 & $20-73$ & \\
\hline 6 months $(n=262)$ & 43 & $20-67$ & \\
\hline $1-2$ years $(n=1124)$ & 46 & $20-80$ & \\
\hline
\end{tabular}

relationship between age and total scale point $(\mathrm{r}=-0.087, \mathrm{p}<$ $0.001)$ and between monthly income and total scale point $(\mathrm{r}=$ $-0.086, \mathrm{p}<0.001)$.

STAI-S scores were compared in terms of the sociodemographic variables in Table 2.

There was a significant difference between employment status groups in terms of total scale point $(p<0.001)$.In pairwise comparisons, it can be seen that government officials have higher scores than employees with government insurance ( $p$ $=0.002)$ than retired people $(\mathrm{p}=0.013)$; healthcareworkers have higher scores than employees with government insurance $(\mathrm{p}<0.001)$, tradesman $(\mathrm{p}=0.001)$,students $(\mathrm{p}=0.016)$ and retired people $(p<0.001)$; housewives have higher scores than employees with government insurance $(\mathrm{p}<0.001)$, tradesman $(\mathrm{p}=0.004)$, students $(\mathrm{p}=0.023)$ and retired people $(\mathrm{p}=0.001)$.

There was a significant difference between monthly income groups in terms of total scale point $(\mathrm{p}<0.001)$ and in pairwise comparisons; it was seen that 'The 3000-5000€' monthly income group has higher scores than 'About 3000£' group ( $\mathrm{p}=$ $0.028)$ and 'Higher than 5000 ”' group ( $\mathrm{p}<0.001)$.

There was a significant difference between household status groups in terms of total scale point $(p=0.001)$ and in pairwise comparisons; the 'Alone' group has higher scores than 'with my wife/husband' group ( $\mathrm{p}<0.001)$, 'With my wife/husband and child/children' group $(\mathrm{p}=0.017)$ and 'only with my parents' group ( $\mathrm{p}=0.017)$.

The association between the other variables and STAI-S scores are listed in Table 3 and Table 4.

There was a significant difference between the most important activities missed in the quarantine period in terms of total scale point $(\mathrm{p}=0.011)$ and in pairwise comparisons; the people who missed travelling to other countries have higher scores than the ones who missed dining outside in restaurants and cafes $(p<0.001)$ and the ones who missed social activities with friends $(\mathrm{p}=0.032)$.

There was a significant difference between the most important causes of anxiety during the pandemic period in terms of total scale point $(\mathrm{p}=0.001)$ and in pairwise comparisons; the people who answered as 'Becoming infected with the virus' has higher scores than 'Someone from my family is infected with the virus' $(p=0.001)$ and 'Decrease in income due to non-work' $(p=0.001)$.

There was a significant difference between the food consumption changes during pandemic period in terms of total scale point $(\mathrm{p}<0.001)$ and in pairwise comparisons, increased group $(p=0.001)$ and decreased groups $(p=0.005)$ have higher scores than 'not changed' group.

There was a significant difference between the groups which have different opinions about the COVID-19 vaccine in terms of total scale point $(\mathrm{p}=0.003)$ and in pairwise comparisons; the people who will prefer to get vaccinated when it is developed has higher scores than the people who will not get vaccinated and do not believe its protective effect $(\mathrm{p}=0.001)$.

There was a significant difference between the estimated end-date for COVID-19 pandemic in terms of total scale point $(\mathrm{p}<0.001)$ and in pairwise comparisons; the people who answered 'I have no hope for ending of the pandemic' have higher scores than the other 3 groups $(\mathrm{p}<0.001)$, $(\mathrm{p}<0.001)$, $(\mathrm{p}=0.009)$. The people who answered ' $1-2$ years' as the enddate have higher scores than the groups who answered ' 3 
months' (p < 0.001) and '6 months' (p < 0.001).

\section{Discussion}

Our study shows that mental health related issues should be taken into consideration for both health care workers and the general population. In our study female gender, younger age, working at a hospital, lower monthly income, living alone and accompanying psychiatric disease were found to be correlated with anxiety levels.

Özdin et al. conducted a survey of the Turkish population to determine the levels and predictors of anxiety during the COVID-19 pandemic and similar to our results; anxiety scores were higher among women [4]. In another study by Zhong et al. which examined the attitudes and practices of Chinese residents during the COVID-19 pandemic, women were found to have more anxiety than men [15]. In another study by Y. Wang et al., women had three times more anxiety than men during the pandemic [16].

In our study there was a significantly negative relationship between age and the total scale point. In a study by Huang et al. general anxiety disorders and depression levels were higher in participants younger than 35 years [17]. A previous study about the SARS outbreak in Taiwan revealed similar results [18]. This may be due to younger individuals spending more time focusing on the outbreak and sharing information on social media or the internet.

Other anxiety related factors were the employment status and monthly income of the participants. Our results showed that health care workers had the highest level of anxiety when compared to other groups similar to the other studies in the literature $[19,20]$. At the beginning of the outbreak, nearly all the doctors irrespective of their clinical specialties started to work in the emergency departments of the hospitals. The increase in their anxiety levels may be due to long working hours, insufficient time to rest and failure to establish social relationships with their families. Several similar studies during other viral outbreaks reported that increased post traumatic stress disorder symptoms are to be expected among health care workers [21, 22].

The anxiety level was found to be decreased with the increase of the monthly income. During the quarantine period in the course of the pandemic, most of the commercial companies were obligated to be closed and this resulted in the decrease of both national and personal income which raised economic uncertainty about the future.

Living alone was another factor in increased anxiety levels. However, in a study by Wang et al. household status did not contribute to anxiety levels in the COVID-19 pandemic [3]. Considering the social structures of the people in our country, sharing our feelingsis one of our most important cultural issues and loneliness may trigger anxiety.

Accompanying psychiatric diseases were also positively related to higher anxiety levels. In the studies by Özdin et al. [4] and Hao et al. [23] similar results were found. During the quarantine period, relatively greater psychological distress occurred in this group of patients who were were more likely to report moderate to severe worries about their physical health due to the concern that they might have been contaminated by the virus and perhaps having less effective coping strategies.

In our study, the participants who increased the number of cigarettes smoked during the pandemic had higher levels of anxiety. Previous studies by Fluharty et al. [24] and O'Toole et al. [25] also showed similar results between the association of smoking and anxiety levels.

During the quarantine period, intercity and international travel options were limited and this also caused increased psychological distress. As a result, anxiety levels were higher in the groups who missed travelling more than other activities.

After the outbreak of the virus in China, the most important precaution emphasized was washing hands after touching possibly contaminated objects. In our study the anxiety levels of participants who increased the number of daily hand wash were higher. Our results were similar with the study during the 2003 SARS-CoV epidemic, in which moderate levels of anxiety were associated with higher uptake of preventive measures by participants [26].

In contrast to other studies, participants in our study whose food consumption decreased during the pandemic had higher anxiety levels. In addition higher level of anxiety was associated with less hours of sleep. Similar results in the literature suggest that sleep disturbance exacerbates anxiety and related disorders [27-29].

Most of the participants had been using media (TV, radio, news and internet) as the primary source of information and watching television increased their anxiety levels. The role of social media was very significant and higher anxiety levels were found in social media users. A study by Eunmi Lee et al. revealed that it was important to deliver effective information on disaster response and strategies to prevent disaster related mental health issues [30]. Governments should use social media more effectively to inform its citizens about a disaster.

Another anxiety related issue was the COVID-19 vaccine. Most of the participants did not have enough knowledge about the vaccine and higher levels of anxiety was found in this group. Currently, various diagnostic kits for testing COVID19 antibodies are available. However the uncertanity of both vaccines and testing methods except the Polymerase Chain Reaction(PCR) test causes more anxiety among people.

It must be kept in mind that viral outbreakshave psychiatric effects as well as biological effects on society and individuals and these psychiatric effects can affect those exposed to this throughout their lives. Hence, mental health policy and services should target a range of psychiatric disorders including post traumatic stress disorder, depression, alcohol abuse, panic disorder and obsessive compulsive disorder both during and after this period. Therefore, emergency physicians, primary care providers and infectious disease specialists should serve to heighten public awareness regarding acute psychiatric events during infectious diseases outbreaks and offer appropriate treatment.

\section{Conclusions}

Viral epidemics, such as COVID-19 result in both medical and psychiatric disorders. Increased anxiety during the pandemic may result in long-term psychiatric disorders which will need to be addressed by health care officials long after the pandemic 
has resolved.

\section{LIMITATIONS}

Our study has several limitations. First, since the data and relevant analyses presented here were derived from a crosssectional design, it is difficult to make causal inferences. Second, the study was limited to the COVID-19 outbreak, and we used a web-based survey method instead of a face to face questionnaire to avoid possible viral transmissions. The sampling method of our study was on a voluntary basis and the survey was conducted by an online system. Third, due to the sudden occurrence of the disaster, we were unable to compare our results with the conditions before the outbreak.

\section{ACKNOWLEDGEMENTS}

The authors would like thank Perihan YILMAZ DILEK, Zeynep ETKESER, Tolga MUHTAR, Tufan SOYUAK, Cihangir GULDOGAN and Prof. Dr. Ridvan ALI for their contributions during the study.

\section{CONFLICT OF INTEREST}

The authors declare no competing interests.

\section{AUTHORS CONTRIBUTION}

VAD and SG designed the research study.DS made the biostatistical analyses. BA, VAD and EA made contribution in the writing part of the manuscript. All authors have read manuscript and approved.

\section{ETHICAL APPROVAL}

Ethical approval was taken from the Scientific Research Commitee of Ministry of Health and Clinical Researches Ethical Commitee of the Uludag University Medical Faculty (20208/14).

\section{DATA AVAILABILITY}

The data used to support the findings of this study are available from the corresponding author upon request.

\section{FUNDING INFORMATION}

This research received no spesific grant from any funding agency in the public, commercial or non-profit sectors.

\section{REFERENCES}

[1] Huang C, Wang Y, Li X, et al. Clinical features of patients infected with 2019 novel coronavirus in Wuhan, China. Lancet. 2020;395:497-506.

[2] Ahorsu D K, Lin C Y, Imani V, et al. The Fear of COVID-19 Scale: development and initial validation. Int J Ment Health Addict. 2020;27;19.

[3] Wang C, Pan R, Wan X, et al. Immediate psychological responses and associated factors during the initial stage of the 2019 coronavirus disease
(COVID-19) epidemic amongthe general population in China. Int $\mathrm{J}$ Environ Res Public Health. 2020;17:1729.

[4] Özdin S, Bayrak Özdin Ş. Levels and predictors of anxiety, depression and health anxiety during COVID-19 pandemic in Turkish society: The importance of gender. Int J Soc Psychiatry. 2020;66:504-511.

[5] Reifels L, Mills K, Dückers MLA, et al. Psychiatric epidemiology and disaster exposure in Australia. Epidemiol Psychiatr Sci. 2019;28:310320.

[6] Murakami M, Takebayashi Y, Takeda Y, et al. Effect of Radiological Countermeasures on Subjective Well-Being and Radiation Anxiety after the 2011 Disaster: The Fukushima Health Management Survey. Int J Environ Res Public Health. 2018;15:124.

[7] Liang Y. Depression and anxiety among elderly earthquake survivors in China. J Health Psychol. 2017;22:1869-1879.

[8] Moise IK, Ruiz MO. Hospitalizations for Substance Abuse Disorders Before and After Hurricane Katrina: Spatial Clustering and AreaLevel Predictors, New Orleans, 2004 and 2008. Prev Chronic Dis. 2016;13:E145.

[9] Spielberger, CD. State-trait anxiety inventory: a comprehensive bibliography, Palo Alto, CA: Mind Garden, 1989.

[10] Bandelow B, Michaelis S. Epidemiology of anxiety disorders in the 21st century. Dialogues Clin Neurosci. 2015;17:327-335.

[11] Spielberger C D, Gorsuch, R L, Lushene R, et al. Manual for the StateTrait Anxiety Inventory. Palo Alto, CA: Consulting Psychologists Press. 1983.

[12] Spielberger C D. Anxiety: Current trends in theory and research: I. Academic Press. 1972.

[13] Emons WH, Habibović M, Pedersen SS. Prevalence of anxiety in patients with an implantable cardioverter defibrillator: measurement equivalence of the HADS-A and the STAI-S. Qual Life Res. 2019;28:3107-3116.

[14] Öner N, Le Compte, A. Durumluk-sürekli kaygı envanteri el kitabı (Manual for the state-trait anxiety inventory-Turkish form) İstanbul: Bogazici University. 1985.

[15] Zhong B L, Luo W, Li H M, et al. Knowledge, attitudes, and practices towards COVID-19 among Chinese residents during the rapid rise period of the COVID-19 outbreak: A quick online cross-sectional survey. Int J Biol Sci. 2020;16:1745-1752.

[16] Wang Y, Di Y, Ye J et al. Study on the public psychological states and its related factors during the outbreak of coronavirus disease 2019 (COVID-19) in some regions of China. Psychol Health Med. 2020. doi: 10.1080/13548506.2020.1746817.

[17] Huang Y, Zhao N. Generalized anxiety disorder, depressive symptoms and sleep quality during COVID-19 outbreak in China: a web-based cross-sectional survey. Psychiatry Res. 2020;288:112954.

[18] Su T P, Lien T C, Yang C Y, et al. Prevalence of psychiatric morbidity and psychological adaptation of the nurses in a structured SARS caring unit during outbreak: a prospective and periodic assessment study in Taiwan. J Psychiatr Res. 2007;41:119-130.

[19] Bohlken J, Schömig F, Lemke MR, et al. COVID-19-Pandemie: Belastungen des medizinischen Personals [COVID-19 Pandemic: Stress Experience of Healthcare Workers - A Short Current Review]. Psychiatr Prax. 2020;47:190-197.

[20] Greenberg N, Docherty M, Gnanapragasam S, et al. Managing mental health challenges faced by healthcare workers during COVID-19 pandemic. BMJ. 2020;368:m1211.

[21] Lee A M , Wong J G, McAlonan G M,et al. Stress and psychological distress among SARS survivors 1 year after the outbreak. Can J Psychiatry. 2007;52:233-240.

[22] Lu Y C, Shu B C, Chang Y Y, et al. The mental health of hospital workers dealing with severe acute respiratory syndrome. Psychother Psychosom. 2006; 75:370-375.

[23] Hao F, Tan W, Jiang L, et al. Do psychiatric patients experience more psychiatric symptoms during COVID-19 pandemic and lockdown? A case-control study with service and research implications for immunopsychiatry. Brain Behav Immun. 2020;87;100-106.

[24] Fluharty M, Taylor AE, Grabski M, et al. The Association of Cigarette Smoking With Depression and Anxiety: A Systematic Review. Nicotine Tob Res. 2017;19:3-13.

[25] O'Toole BI, Kirk R, Bittoun R et al. Combat, Posttraumatic Stress 
Disorder, and Smoking Trajectory in a Cohort of Male Australian Army Vietnam Veterans. Nicotine Tob Res. 2018;20:1198-1205.

[26] Leung G M. The impact of community psychological responses on outbreak control for severe acute respiratory syndrome in Hong Kong. J. Epidemiol. Community Health. 2003;57:857-863.

[27] Mikolajczyk RT, El Ansari W, Maxwell AE. Food consumption frequency and perceived stress and depressive symptoms among students in three European countries. Nutr J. 2009;8:31.

[28] Cox RC, Olatunji BO. A systematic review of sleep disturbance in anxiety and related disorders. J Anxiety Disord. 2016;37:104-129.

[29] Razzoli M, Pearson C, Crow S, et al. Stress, overeating, and obesity: Insights from human studies and preclinical models. Neurosci Biobehav
Rev. 2017;76:154-162.

[30] Lee E, Lee H. Disaster awareness and coping: Impact on stress, anxiety, and depression. Perspect Psychiatr Care. 2019;55:311-318.

How to cite this article: Vahide Aslihan Durak, Şeyda Gunay, Deniz Sigirli, Bedrettin Akova, Erol Armagan. COVID-19 Pandemic and Anxiety Related Factors in Patients Treated in the Emergency Department. Signa Vitae. 2020;16(2):167-174. doi: 10.22514/sv.2020.16.0051. 